\title{
ANALISIS ASURANSI PENGANGGURAN DENGAN ASUMSI NON-ZERO MORTALITY
}

\section{Unemployment Insurance Analysis with Non-Zero Mortality Assumptions I Nyoman Widana $^{1 *}$, I Putu Winada Gautama ${ }^{2}$ \\ 1,2 Prodi Matematika, Fakultas Matematika dan Ilmu Pengetahuan Alam, Universitas Udayana Jl. Raya Kampus UNUD, Bukit Jimbaran, Badung, 80361, Indonesia}

Corresponding authore-mail: 1*widana@unud.ac.id

\begin{abstract}
Abstrak
Indonesia dengan jumlah penduduk sekitar 267 juta jiwa memiliki angkatan kerja sangat besar. Tetapi jumlah lapangan kerja yang tersedia tidak mampu menyerap semua angkatan kerja ini. Selain itu angka pemutusan hubungan kerja juga relatif masih tinggi. Hal ini membuat pemerintah melontarkan wacana program asuransi pengangguran. Sejauh ini telah dilakukan studi tentang hubungan besar premi dan benefit dari asuransi pengangguran. Tetapi, model yang digunakan dalam perhitungan preminya, dibentuk berdasarkan asumsi zero mortality. Tujuan dari penelitian ini adalah menganalis asuransi pengangguran dengan asumsi non-zero mortality. Metode yang digunakan adalah The Equivalence Principle. Hasil Perhitungan menunjukkan tarif premi untuk non-zero mortality nilainya lebih kecil dari pada tarif premi untuk zero mortality.
\end{abstract}

Kata Kunci: Asuransi Pengangguran, Non-Zero Mortality, Premi.

\begin{abstract}
Indonesia, with a population of around 267 million people, has a very large workforce. However, the number of available jobs cannot absorb all of this workforce. In addition, the unemployment rate is still relatively high. This has prompted the government to implement an Unemployment Insurance Program. A number of studies have been carried out to value the benefits and appropriately price the policy. These studies calculated the premium with the assumption of zero mortality. The aim of this research is to analyze unemployment insurance with the assumption of non-zero mortality. The method used is the equivalence premium principle. The result shows that the premium rate for the nonzero mortality model is smaller than the premium rate for the zero mortality model.
\end{abstract}

Keywords: Non-zero Mortality, Premium, Unemployment Insurance

Article info:

Submitted: 02 $2^{\text {th }}$ July 2021 Accepted: $30^{\text {th }}$ August 2021

How to cite this article:

I N. Widana, and I P. W. Gautama, "ANALISIS ASURANSI PENGANGGURAN DENGAN ASUMSI NON-ZERO MORTALITY”, BAREKENG: J. Il. Mat. \& Ter., vol. 15, no. 03, pp. 575-580, Sep. 2021.

This work is licensed under a Creative Commons Attribution-ShareAlike 4.0 International License. Copyright @ 2021 I Nyoman Widana, I Putu Winada Gautama 


\section{PENDAHULUAN}

Indonesia dengan jumlah penduduk sekitar 267 juta jiwa memiliki angkatan kerja sangat besar. Tetapi jumlah lapangan kerja yang tersedia tidak mampu menyerap semua angkatan kerja ini. Menurut Badan Pusat Statistik (BPS) angka pengangguran mencapai 7,05 juta orang pada Agustus 2019. Angka pengangguran ini meningkat sebesar 50 ribu orang dibandingkan tahun 2018 [1]. Selain itu angka pemutusan hubungan kerja (PHK) juga relatif masih tinggi. Hal ini membuat pemerintah melontarkan wacana program asuransi pengangguran (unemployment insurance) yang diharapkan bisa meringankan beban finansial yang harus ditanggung oleh pekerja yang mengalami PHK.

Asuransi pengangguran adalah jaminan sosial yang diberikan oleh perusahan asuransi bagi peserta asuransi yang kehilangan pekerjaannya. Asuransi ini pertama kali didirikan oleh Foundry Men`s Union di Britania pada tahun 1832 [16]. Adapun tujuannya adalah untuk menanggulangi sebagian dari masalah finansial yang diakibatkan oleh PHK. Untuk bisa memperoleh manfaat (benefit) dari program ini, peserta diwajibkan menyetor sejumlah uang (premi) yang besarnya berkaitan dengan besarnya upah atau penghasilan yang diterima [6], [11]. [15].

Sesuai Konvensi ILO pengangguran yang memenuhi syarat untuk mendapatkan uang pertanggungan dari program asuransi pengangguran cakupan areanya meliputi: (1) pengangguran itu harus tidak dikehendaki (involuntary unemployment), (2) pengangguran harus bersifat tidak permanen, (3) penganggur, yang akan mendapat benefit ini, harus telah mempunyai pekerjaan sebelumya (bukan yang untuk baru mau bekerja), (4) penganggur tersebut harus tetap mampu bekerja, (5) penganggur harus tetap sanggup untuk bekerja kembali, dan (6) penganggur harus bersedia menerima pekerjaan yang layak (suitable employment) [4], [10].

Asuransi pengangguran tentunya sangat berguna bagi pekerja yang menghadapi pemutusan PHK atau menganggur. Selain itu, program ini dapat juga diusulkan sebagai salah satu solusi mengatasi masalah kemiskinan dan kesejangan di Indonesia [3]. Sejauh ini Badan Penyelenggara Jaminan Sosial (BPJS) yang bertugas memberikan perlindungan pekerja hanya menawarkan program jaminan kecelakaan kerja, jaminan kematian, jaminan hari tua, dan dana jaminan pensiun. Perlu juga dicatat bahwa beberapa negara maju sudah menerapkan program asuransi pengangguan. Sehingga untuk itu program Asuransi Pengangguran perlu dikaji sebagai salah satu opsi untuk menyelesaikan problem sosial yang diakibatkan oleh adanya PHK..

Pada tahun 2010, Chuang. dan Yu telah mengestimasi durasi menganggur dan menghitung tarif premi untuk asuransi pengangguran. Pada penelitiannya, mereka menggunakan data yang bersumber dari program asuransi pengangguran di Taiwan. Model distribusi Weibull digunakannya untuk mengestimasi rata-rata lama menganggur. Sedangkan capital asset pricing model digunakan untuk mengestimasi tingkat suku bunga. Besarnya premi untuk asuransi pengangguran berkisar antara 0,5231\% - 0,6982\% dari gaji [7]. Simwa et al (2016) menghitung harga premi dari asuransi pengangguran dengan mengasumsikan durasi menganggur mengikuti distribusi Burr XII Mixture [12]. Tahun 2018, Simwa meneliti harga premi untuk asuransi pengangguran di USA. Hasil penelitiannya menunjukan bahwa besarnya premi yg dihitung dengan menggunakan asumsi non-zero mortality adalah 4,07\% [14]. Pada penelitian-penelitian tersebut, premi yang dihitung adalah premi bersih (netto). Berdasarkan uraian-uraian sebelumnya, penelitian ini bertujuan menganalisis premi kotor (brutto) dari asuransi pengangguran dengan menggunakan asumsi non-zero mortality. Besar biaya asuransi yang dibebankan kepeserta adalah sebesar $0,4 \%$ dari gaji [9]. Tabel Mortalitas Taspen akan digunakan untuk menentukan peluang hidup dari peserta asuransi [2].

\section{METODE PENELITIAN}

Tahapan yang dilakukan untuk mencapai tujuan penelitian ini adalah sebagai berikut:

1. Membentuk persamaan untuk menentukan premi dari asuransi pengangguran. Untuk itu, mula-mula akan dihitung ekspektasi nilai tunai dari pembayaran premi asuransi pengangguran. Kemudian akan dihitung ekspektasi besar manfaat asuransi pengangguran untuk tingkat penggantian (replacement rate) sebesar $50 \%$ dari besar gajinya. Setelah itu ditentukan ekspektasi nilai tunai dari biaya administrasi.

2. Mengumpulkan data unemployment rate dari Biro Pusat Statistik (BPS).

3. Mengestimasi jumlah peserta program asuransi pengangguran yang akan mengajukan klaim benefit dalam waktu satu tahun.

4. Menghitung peluang hidup usia pecahan dari seseorang peserta asuransi pengangguran.

5. Menghitung tarif premi (premium rate) dari asuransi pengangguran.

6. Menganalisis hubungan besar tarip premi untuk asumsi zero mortality dan non-zero mortality. 


\section{HASIL DAN PEMBAHASAN}

\subsection{Persamaan untuk Menentukan Premi dari Asuransi Pengangguran}

Premi untuk asuransi pengangguran dihitung berdasarkan equivalence principle

$$
E[L]=0
$$

yaitu ekspektasi dari kerugian adalah nol. Ini mengakibatkan ekspektasi nilai tunai dari premi sama dengan ekpektasi nilai tunai dari santuan (benefit) ditambah nilai tunai dari biaya [5], [8], [13].

$$
E P V(P)=E P V(B)+E P V(E)
$$

Dengan

$E P V(P)=$ Ekspektasi nilai tuani dari premi

$E P V(B)=$ Ekspektasi nilai tunai dari santuan (benefit)

$E P V(E)=$ Ekspektasi nilai tuani dari biaya

Asumsi yang digunakan untuk menghitung nilai preminya adalah sebagai berikut:

1. Batas usia pensiun adalah 58 tahun.

2. Asuransi pengangguran ini berjangka 1 tahun. Pembayaran premi dan biaya dilakukan setiap awal bulan selama satu tahun.

3. Tingkat kematian sesaat (force of mortality) bernilai konstan untuk $x$ bilangan bulat dan $0 \leq s<1$

$$
\mu_{x+s}=\mu_{x}^{*}
$$

4. Pembayaran santunan (benefit), sebesar $50 \%$ dari gaji, dilakukan selama tiga bulan dan dilakukan diakhir bulan.

5. Biaya administrasi diasumsikan sebesar $0,4 \%$ dari gaji [9].

6. Besar peluang terjadinya klaim sama setiap bulan dan nilainya sama dengan tingkat pengangguran (unemployment rate)

Misalkan $S$ menyatakan besar gaji per bulan dari peserta program asuransi pengangguran dan $W$ menyatakan tarif preminya (premium rate). Maka nilai tunai dari premi untuk asuransi berjangka, untuk model non-zero mortality, adalah

$$
\operatorname{EPV}(P)=W S \sum_{k=o}^{11}(1+r)^{-\frac{k}{12}}{ }_{\frac{k}{12}} p_{x}
$$

Dengan $r$ menyatakan tingkat bunga setahun.

Perhitungan nilai tunai dari benefit sebesar 50\% dari gaji diberikan oleh [4]

$$
E P V(B)=\sum_{k=1}^{11}(1+r)^{-\frac{k}{12}} q_{k}^{u}(0,50-W) S \sum_{t=o}^{2}(1+r)^{-\frac{k}{12}} \frac{k+t}{12} p_{x}
$$

Dengan

$q_{u}^{k}$ menyatkan peluang terjadinya klaim di bulan ke- $k$

Selanjutnya, nilai tunai dari biaya administrasinya adalah

$$
E P V(P)=0,004 S \sum_{k=o}^{11}(1+r)^{-\frac{k}{12}} \frac{k}{12} p_{x}
$$

Dari persamaan (1), (2), (3), dan (4) diperoleh

$$
W=\frac{\sum_{k=1}^{12} 0,50(1+r)^{-\frac{k}{12}} q_{k}^{u} \sum_{t=o}^{b}(1+r)^{-\frac{t}{12}}{ }_{\frac{k+t}{12}} p_{x}+0,004 \sum_{k=o}^{11}(1+r)^{-\frac{k}{12}} \frac{k}{12} p_{x}}{\sum_{k=o}^{11}(1+r)^{-\frac{k}{12}}{ }_{\frac{k}{12}} p_{x}+\sum_{k=1}^{12}(1+r)^{-\frac{k}{12}} q_{k}^{u} \sum_{t=o}^{2}(1+r)^{-\frac{t}{12}}{ }_{\frac{k+t}{12}} p_{x}}
$$


Persamaan (5) ini menyatakan tariff premi brutto yang dihitung dengan menggunakan asumsi non-zero mortality serta pembayaran preminya dilakukan setiap bulan selama satu tahun.Perlu dicatat bahwa jika diasumsikan $p_{x}=1$ maka persamaan (5) dapat ditulis dalam bentuk

$$
W=\frac{\sum_{k=1}^{12} 0,50(1+r)^{-\frac{k}{12}} q_{k}^{u} \sum_{t=o}^{b}(1+r)^{-\frac{t}{12}}+0,004 \sum_{k=o}^{11}(1+r)^{-\frac{k}{12}}}{\sum_{k=o}^{11}(1+r)^{-\frac{k}{12}}+\sum_{k=1}^{12}(1+r)^{-\frac{k}{12}} q_{k}^{u} \sum_{t=o}^{2}(1+r)^{-\frac{t}{12}}}
$$

Persaman (6) adalah tarif premi untuk asumsi tidak ada peserta yang meninggal (zero mortality).

\subsection{Tarif Premi (Premium Rate)}

Pada bagian ini akan dihitung tarif premi asuransi pengangguran dengan menggunakan asumsi nonzero mortality dan zero mortality, untuk tingkat usia peserta antara $18-57$ tahun. Adapun tabel mortalitas yang digunakan adalah Tabel Mortalita Taspen. Tingkat bunga setahun yang akan digunakan dalam perhitungan tarif premi ini besarnya adalah 5\%. Sedangkan peluang terjadinya klaim akan dihitung berdasarkan data tingkat pengangguran (unempoyent rate) yang bersumber dari Biro Pusat Statistik.

Data mengenai tingkat pengangguran (unemployment rate) dari tahun 2000-2019 disajikan oleh Tabel 1 berikut:

Tabel 1 Tingkat Pengangguran

\begin{tabular}{lcccccccccc}
\hline Tahun & $\mathbf{2 0 0 0}$ & $\mathbf{2 0 0 1}$ & $\mathbf{2 0 0 2}$ & $\mathbf{2 0 0 3}$ & $\mathbf{2 0 0 4}$ & $\mathbf{2 0 0 5}$ & $\mathbf{2 0 0 6}$ & $\mathbf{2 0 0 7}$ & $\mathbf{2 0 0 8}$ & $\mathbf{2 0 0 9}$ \\
\hline $\begin{array}{l}\text { Unemployment } \\
\text { Rate }(\%)\end{array}$ & 6,08 & 6,08 & 6,60 & 6,66 & 7,30 & 7,95 & 7,55 & 8,06 & 7,21 & 6,11 \\
\hline Tahun & $\mathbf{2 0 1 0}$ & $\mathbf{2 0 1 1}$ & $\mathbf{2 0 1 2}$ & $\mathbf{2 0 1 3}$ & $\mathbf{2 0 1 4}$ & $\mathbf{2 0 1 5}$ & $\mathbf{2 0 1 6}$ & $\mathbf{2 0 1 7}$ & $\mathbf{2 0 1 8}$ & $\mathbf{2 0 1 9}$ \\
\hline $\begin{array}{l}\text { Unemployment } \\
\text { Rate }(\%)\end{array}$ & 5,61 & 5,15 & 4,47 & 4,34 & 4,05 & 4,51 & 4,30 & 4,19 & 4,30 & 4,38 \\
\hline
\end{tabular}

Sumber data: Biro Pusat Statistik

Berdasarkan Tabel 1 diperoleh rata-rata tingkat pengangguran (RTP) yang diasumsikan sama dengan peluang terjadinya klaim, $q_{u}^{k}$ adalah

$$
q_{u}^{k}=R T P=0,05 \text { per tahun }=\frac{1}{240} \text { per bulan }
$$

Selanjutnya, dari asumsi $\mu_{x+s}=\mu_{x}^{*}$ diperoleh hubungan ${ }_{s} p_{x}=\left(p_{x}\right)^{s}, \quad 0 \leq s<1$ [7]. Nilai $p_{x}=l_{x+1} / l_{x}$ dihitung menggunakan Tabel Mortalita Taspen.

Tarif premi, dengan asumsi non-zero mortality, untuk peserta dengan usia $x=57$ dapat dihitung dengan menggunakan persaaman (5)

$$
\begin{aligned}
W & =\frac{\sum_{k=1}^{12} 0,50(1+0,05)^{-\frac{k}{12}} \frac{1}{240} \sum_{t=o}^{2}(1+0,05)^{-\frac{t}{12}} \frac{k+t}{12} p_{57}+0,004 \sum_{k=o}^{11}(1+0,05)^{-\frac{k}{12}} \frac{k}{12} p_{57}}{\sum_{k=o}^{11}(1+0,05)^{-\frac{k}{12}} \frac{k}{12} p_{57}+\sum_{k=1}^{12}(1+0,05)^{-\frac{k}{12}} \frac{1}{240} \sum_{t=o}^{2}(1+0,05)^{-\frac{t}{12}} \frac{k+t}{12} p_{57}} \\
& =0,010065
\end{aligned}
$$

Sedangkan tarif premi, dengan asumsi zero mortality dapat dihitung dengan menggunakan persamaan (6)

$$
W=\frac{\sum_{k=1}^{12} 0,50(1+0,05)^{-\frac{k}{12}} \frac{1}{240} \sum_{t=o}^{2}(1+0,05)^{-\frac{t}{12}}+0,004 \sum_{k=o}^{11}(1+0,05)^{-\frac{k}{12}}}{\sum_{k=o}^{11}(1+0,05)^{-\frac{k}{12}}+\sum_{k=1}^{12}(1+0,05)^{-\frac{k}{12}} \frac{1}{240} \sum_{t=o}^{2}(1+0,05)^{-\frac{t}{12}}}=0,010075
$$

Tarif pemi selengkapnya untuk peserta berusia antara 18 - 57 tahun disajikan pada Gambar 1. 


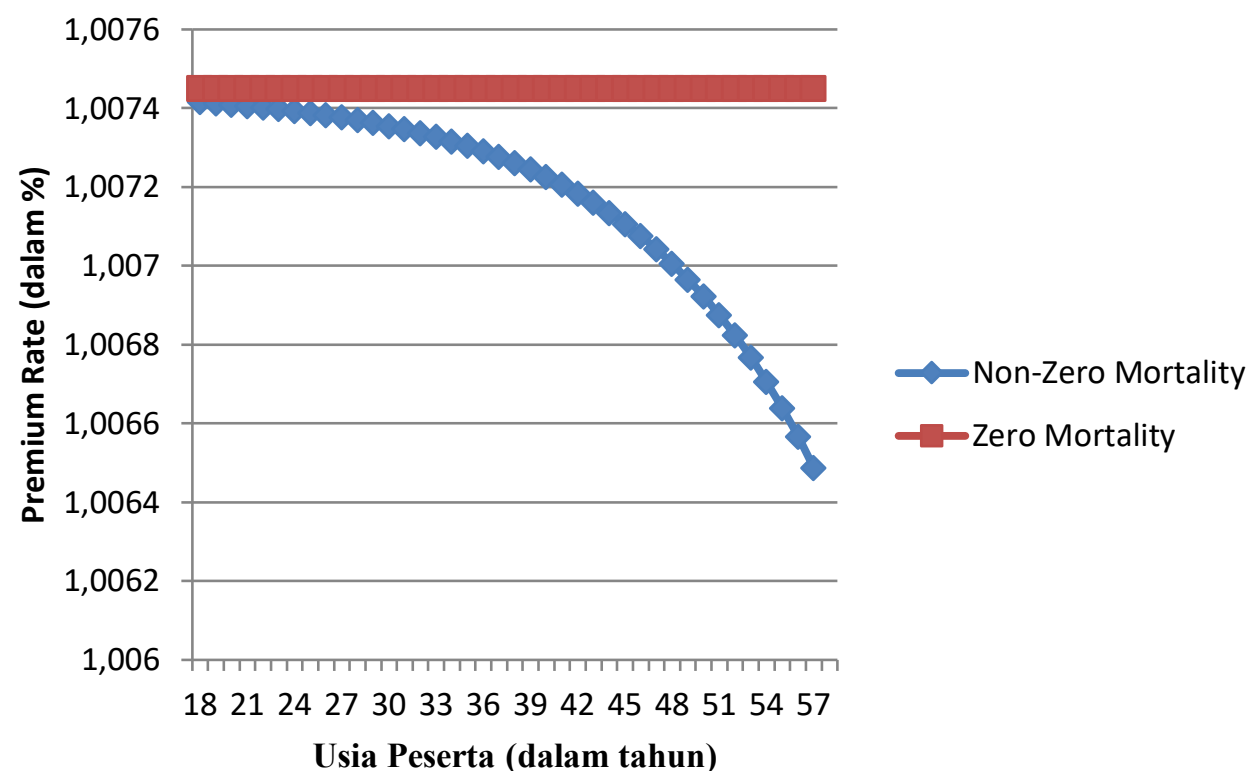

Gambar 1. Grafik tarif premi untuk non-zero mortality dan zero mortality

Dari Gambar 1 terlihat bahwa tarif premi untuk model non-zero mortality akan semakin menurun seiring bertambahnya usia dari peserta program asuransi pengangguran. Tarif premi per tahunnya berkisar antara $1,0065 \%-1,0074 \%$. Sedangkan untuk zero mortality besar tarifnya adalah $1,0075 \%$ dari besarnya gaji. Perlu juga dicatat bahwa harga premi dengan menggunakan asumsi non-zero mortality lebih murah daripada harga premi yang dihitung berdasarkan asumsi zero mortality.

\section{KESIMPULAN}

Hasil perhitungan menunjukkan tarif premi (premium rate) untuk model non-zero mortality nilainya lebih kecil dari pada tarif premi untuk model zero mortality. Tarif premi per bulan untuk model non-zero mortality berkisar antara $1,0065 \%-1,0074 \%$ dari besarnya gaji, tergantung dari usia peserta program asuransi pengangguran ini. Sedangkan untuk zero mortality besar tarifnya adalah $1,0075 \%$ dari besarnya gaji.

\section{DAFTAR PUSTAKA}

[1] Badan Pusat Statistik, Statistik Indonesia, BPS, 20 Desember 2020, [Online]. Tersedia: https://www.bps.go.id/ [Diakses 8 Desember 2020].

[2] Biro Pusat Aktuaria , “TMT 2012 Tabel Mortalita Taspen 2012," Aktuaria, 20 Juli 2012 [Online]. Tersedia: http://docshare04.docshare.tips/files/21195/211956752.pdf [Diakses: 20 Desember 2020].

[3] BPJS Ketenagakerjaan, "Laporan tahunan 2017," Bpjsketenakerjaan, 1 Desember 2017, [Online]. Tersedia: www.bpjsketenagakerjaan.go.id [Diakses 8 Mei 2019]

[4] C. Stone and W. Chen, Introduction to Unemployment Insurance, Cbpp 30 Juli 2014. [Online]. Tersedia: https://www.cbpp.org/research/introduction-to-unemployment-insurance

[5] D.C.M Dickson., M.R. Hardy. \& H.R. Waters, Actuarial Mathematics for Life Contingent Risk. New York: Cambridge University Press, 2013.

[6] G.J Hwang (2019), How fair are unemployment benefits? The experience of East Asia. Wiley, 29 April 2019, [Online]. Tersedia: https://doi.org/10.1111/issr.12202

[7] H.L. Chuang and M.T. Yu, "Pricing Unemployment Insurance-An Umployment-Duration-Adjusted Approach," ASTIN Bulletin, vol. 40, Issue 2, pp. 519-545, 2010.

[8] H.U. Gerber Gerber, Life Insurance Mathematics, 3rd edition. Berlin: Springer, 1997

[9] International Labour Organization 2003, The Feasibility of Introducing an Unemployment Insurance Benefit in Indonesia, Ilo, 30 Desember 2003, [Online]. Tersedia: https://www.ilo.org [Diakses pada tanggal 8 Agustus 2020]. 
[10] I. N. Widana dan K. Jayanegara , “Analisis Premi dari Asuransi Pengangguran,” Jurnal Matematika, vol 9 no. 1 pp. 60-65, 2019

[11] S L. Gajek and K.M. Ostaszewski, Financial Risk Management for Pension Plans. Amsterdam: Elsevier, 2004

[12] M.M. Kithinji, R.O. Simwa, and J.A.M. Otieno "Pricing Unemployment Insurance Assuming Burr Xii Mixture Distribution To Model Unemployment," International Journal of Statistical Distributions andApplications, vol. 2, No 3, pp. 27-34, 2016.

[13] N.L. Bowers, H.U. Gerber, J.C. Hickman, D.A. Jones, and C.J. Nesbitt, Actuarial Mathematics, 2nd edition. Schaumburg: The Society of Actuaries, 2017.

[14] R.O. Simwa, "On Pricing of Unemployment Insurance Assuming Non-Zero Mortality for Employees with Application to the USA,” European Journal of Statistics and Probability, vol. 6, No. 2, pp. 1-11, 2018.

[15] S.U. Adillah, "Kebijakan Jaminan Sosial Tenaga Kerja Sektor Informal Berbasis Keadilan Sosial untuk Meningkatkan Kesejahteraan," Yustisia, vol 4 no. 3, pp. 558-580, 2015

[16] Z. Ragiliawan dan B.T. Gunawan, "Kehilangan Pekerjaan (JKP) dalam Perspektif Belanja Negara”, Jurnal Ketenagakerjaan, vol. 15, No 1, pp. 48-60, 2021 